\title{
Microstructure of Alumina-Matrix Composites Reinforced with Nanometric Titanium and Titanium Carbide Dispersions
}

\author{
Elizabeth Refugio-García ${ }^{a}$ David Hernández-Silva ${ }^{\mathrm{b}}$, Eduardo Terrés-Rojas $^{\mathrm{c}}$, \\ José Amparo Rodríguez-García ${ }^{\mathrm{d}}$,Enrique Rocha-Rangel ${ }^{\mathrm{d} *}$ \\ ${ }^{a}$ Departamento de Materiales, Universidad Autónoma Metropolitana, \\ Av. San Pablo, 180, D.F. 02200, Col Reynosa, Tamaulipas, México \\ ${ }^{\mathrm{b}}$ Departamento de Ingeniería Metalúrgica, ESIQIE-IPN, UPALM, \\ Av. IPN s/n, D.F. 07738, San Pedro Zacatenco, México \\ ${ }^{ }$Laboratorio de Microscopía Electrónica de Ultra Alta Resolución, IMP, \\ Eje Central Lazara Cárdenas, 152, D.F. 07730, San Bartolo Atepehuecan, México \\ ${ }^{\mathrm{d}}$ Universidad Politécnica de Victoria, Av. Nuevas Tecnologías 5902, \\ Parque Científico y Tecnológico de Tamaulipas, D.F. 87137, Ciudad Victoria, Tamaulipas, México
}

Received: March 1, 2012; Revised: May 29, 2012

\begin{abstract}
The synthesis of alumina $\left(\mathrm{Al}_{2} \mathrm{O}_{3}\right)$-composites having different amount of very fine titanium and titanium carbide reinforcement-particles has been explored. Two experimental steps have been set for the synthesis; the first step consisted of the pressureless-sintering of $\mathrm{Al}_{2} \mathrm{O}_{3}$-titanium powders which were thoroughly mixed under high energy ball-milling and through the second step it was induced the formation of titanium carbide during different times at $500{ }^{\circ} \mathrm{C}$ by the cementation packing process. SEM and EDS analysis of the microstructures obtained in both sintered and cemented bodies were performed in order to know the effect of the activated carbon used as cementing agent on the titanium for each studied composite. It was observed that a titanium carbide layer growth from the surface into the bulk and reaches different depth as the titanium content in the composites increases. On the other hand, the use of ductile titanium notably enhanced density level and fracture toughness of the composites.
\end{abstract}

Keywords: alumina-composites, metallic-renforcements, cementation packing process

\section{Introduction}

Alumina $\left(\mathrm{Al}_{2} \mathrm{O}_{3}\right)$ is the most widely used ceramic and is considered an important industrial material, due to its good mechanical properties such as: high hardness, high compressive strength in combination with good chemical and thermal stability ${ }^{1-2}$. However, its applications as a structural material have been limited due to its low fracture toughness. This is because cracks easily propagate in this ceramics and therefore they might cause unpredictably fail in service. The incorporation of several reinforcement materials such as; ceramics, metals and intermetallics compounds into an $\mathrm{Al}_{2} \mathrm{O}_{3}$ matrix forming a composite material has been proved to be an effective experimental route to improve toughness of the ceramic matrix ${ }^{3}$. In consequence, they can be used, for example in application at high temperatures such as in the construction of gas turbine engines in order to increase their thermal cycle efficiency ${ }^{4-5}$. Therein, the mechanical and physical properties of such type of composites have been studied, as well as their manufacture processes ${ }^{6-8}$. In spite of this, the high temperature cementation of metallic carbide-dispersed composites has not been investigated in detail and there are not sufficient reports on the high temperature cementation

*e-mail: erochar@upv.edu.mx of thermal barrier composite-coatings ${ }^{9}$. Since elemental carbon may diffuse throughout an oxide matrix at high temperatures, the metallic particles dispersed in a matrix can consequently be cemented. The Pack cementation process has been used for many years to develop protection coating in different materials, principally metallic alloys. Here the body is essentially heat treated in a reactive environment to chemically modify the surface region, thus forming ceramic compounds that improve hardness, corrosion and heat resistance. Variables that affect the quality of coating includes body composition, powder bed composition, and heat treating conditions such as temperature, time and furnace atmosphere.

\section{Experimental Procedure}

Composite materials were prepared using two consecutive steps. First, titanium-dispersed oxide aluminium composites were prepared using precursor powders of $\mathrm{Al}_{2} \mathrm{O}_{3}(99.9 \%$, $1 \mathrm{~mm}$, Sigma, USA) and Ti (99.9\%, 1-2 mm, Aldrich, USA). The amount of powder was selected as to obtain $\mathrm{Al}_{2} \mathrm{O}_{3}$-based composites having $0.5,1,2$ and 3 vol. $\%$ of Ti. The powder mixture was ball-milled in a commercial high energy mill (Simoloyer) using $\mathrm{ZrO}_{2}$ balls (with $\mathrm{Si}_{3} \mathrm{~N}_{4}$-inner coating to 
avoid contamination), the rotational speed of which was set to $400 \mathrm{rpm}$ for 8 hours. The ball-to-powder volume ratio was set to $20: 1$. Using milled powder mixtures, cylindrical samples of $2 \mathrm{~cm}$ diameter and $0.3 \mathrm{~cm}$ thick were fabricated by uniaxially pressing $2 \mathrm{~g}$ at $250 \mathrm{MPa}$. Cold-pressed green samples were then pressureless sintered in an electric furnace using argon atmosphere. Heating rate was set to $10^{\circ} \mathrm{C} / \mathrm{min}$, sintering temperature was $1400^{\circ} \mathrm{C}$ and holding time 1 hour. After sintering, furnace was turned off and samples were left inside it for gradual cooling. Then, for second step, the composites were cemented as follows; the composite powder, produced as described before, was placed inside a graphite-made container. Inside the container the sintered-compact sample was totally surrounded by the cementing medium (powdered activated carbon) and then heated in vacuum up to $500^{\circ} \mathrm{C}$ for $1,2,4$ and 8 hours. The later set arranged in order to induce carbon diffusion into the sample and to cement titanium particles that are found near the surface of the composite, before being allowed to cool down inside the furnace.

The specimen's characterization was conducted like so; density of fired specimens was determined using the Archimedes' method. Cemented samples were analyzed using scanning electron microscopy SEM (XL30 ESEM, Philips) and energy dispersive spectroscopy EDS (Noram), to observe their microstructure and chemical composition, respectively. Thickness of the carbide (cemented) layer as a function of the titanium content and cemented time in each sample was also determined by using these techniques. Microhardness of the obtained specimens was evaluated using Vickers indentation in a microhardener (Buehler Micromet 2003), whereas their toughness was estimated following the fracture indentation method ${ }^{10}$.

\section{Results and Discussion}

Size and morphology of alumina-titanium mixture powders after the milling stage is shown in Figure 1. This figure shows agglomerated particles, the formation of the agglomerated is due to the very small size of the particles after the milling stages; the particle size of the powder mixture is in the order of nanometers $(\sim 200 \mathrm{~nm})$. This photograph shows round particle shapes, typical of conventional high energy milled powder. A good dispersion between titanium and alumina particles is expected.

Figure 2 shows scanning electron micrographs of the alumina-3 vol.\% Ti composite. Suitably refined and homogeneous microstructures are achieved in the sample. The ligament diameter (titanium-white particles) ranges from less than $1 \mu \mathrm{m}$, for all samples it appears to be independent of the amount of titanium in the composite. The grain size of alumina ranges from 5 to $10 \mu \mathrm{m}$ and it appears not to grow up with the increments of $\mathrm{Ti}$ in the composite. In this picture it is possible to observe some small porosity in the sample. In all samples, the alumina-matrix and reinforcing metallic particles were identified with the help of EDS analysis performed during SEM observations two spectra of this analysis carry out on the surface and in the core of the sample with 3 vol.\% Ti are show in Figure 2. These spectra show a composite with homogeneous composition on the surface of the sample as well in the core of the same one.
The cross section view of prepared composite-specimens, as a function of the cementation process time at $500{ }^{\circ} \mathrm{C}$, is shown in Figure 3. These fractographs reveal general features of the microstructure and equiaxial grains for the 3 vol.\% Ti specimens. It is evident the formation of homogeneous specimens, because the Ti particles (typically disclosed by SEM as tiny white dots), which retained their very fine sizes, were well distributed in the alumina matrix (gray-dark phase). In general, the resulting microstructures displayed few pores left in the matrix after sintering. In these pictures, it can also be observed that there are not Ti particles in the surface region to a depth of about 40 , 75, 100 and $107 \mu \mathrm{m}$ for samples cemented during 1, 2, 4 and 8 hours, respectively. The local region in which Ti-particles have reacted with diffusing carbon is defined to as the cemented zone, whose thickness turns into layer depending on the gradient concentration and sintering time. A common factor in all pictures shown in Figure 3 relates to the fact that $\mathrm{Al}_{2} \mathrm{O}_{3}$-based composites do not fracture by the Ti-cementation.

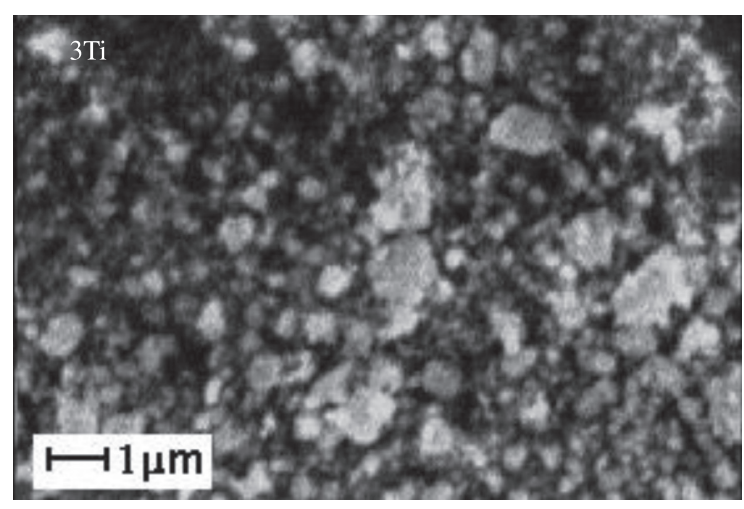

Figure 1. Size and morpholgy of alumina-3 vol.\% Ti powders after mixing.

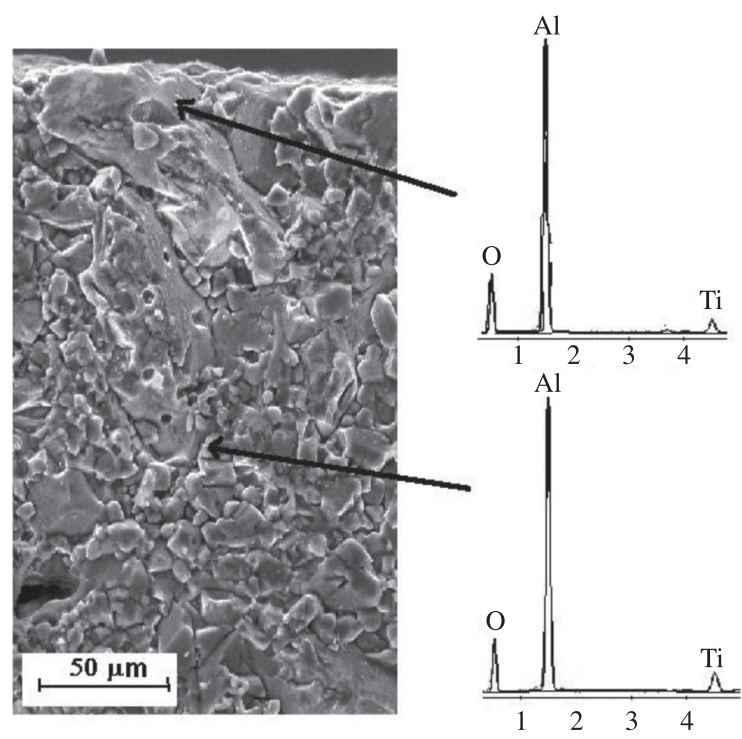

Figure 2. SEM and EDS analyses of alumina-3 vol.\% Ti sintered composite. 


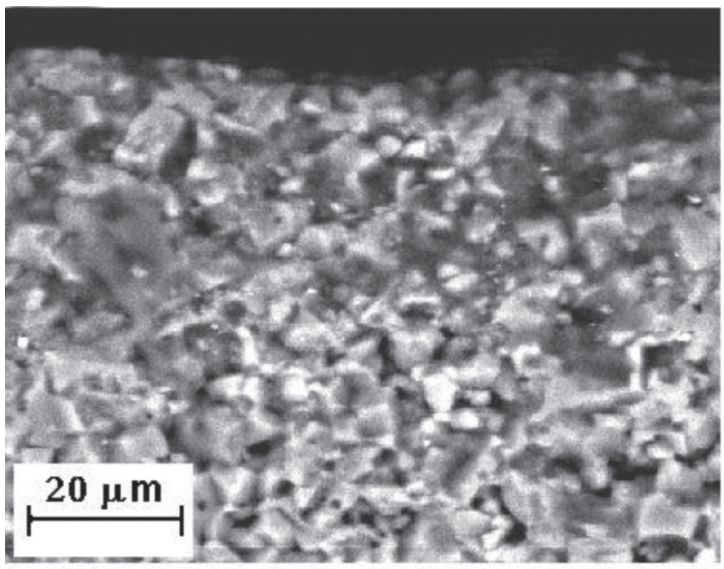

(a)

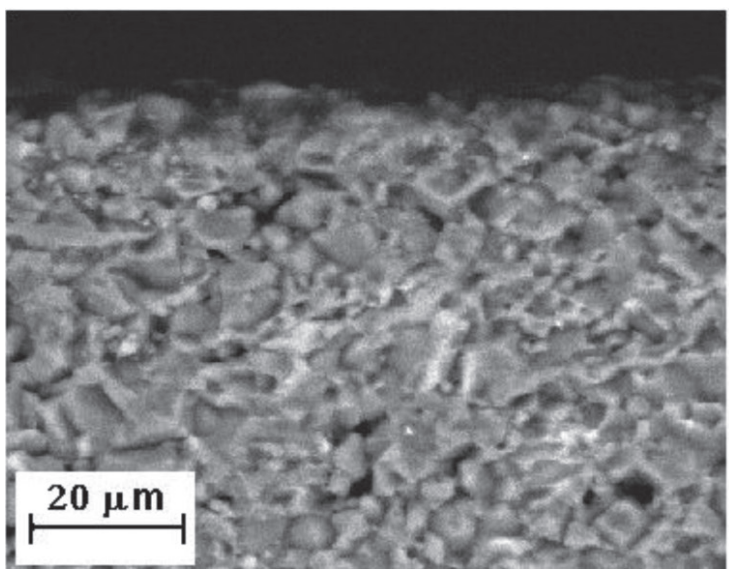

(c)

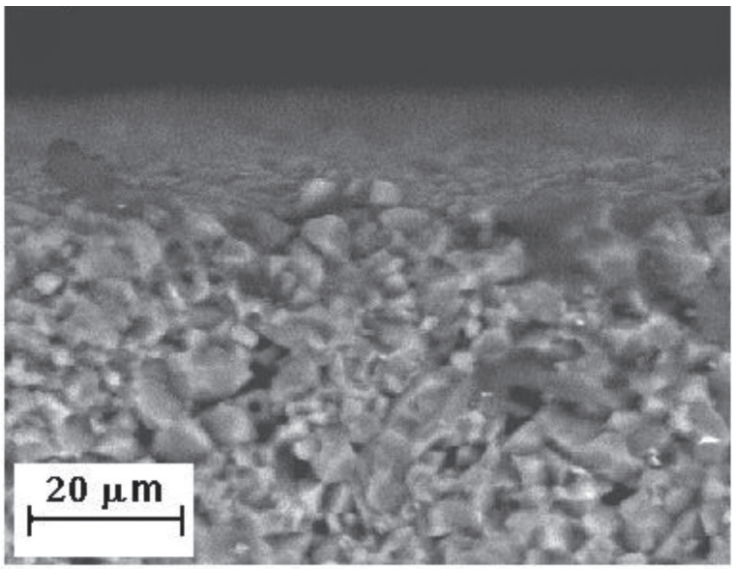

(b)

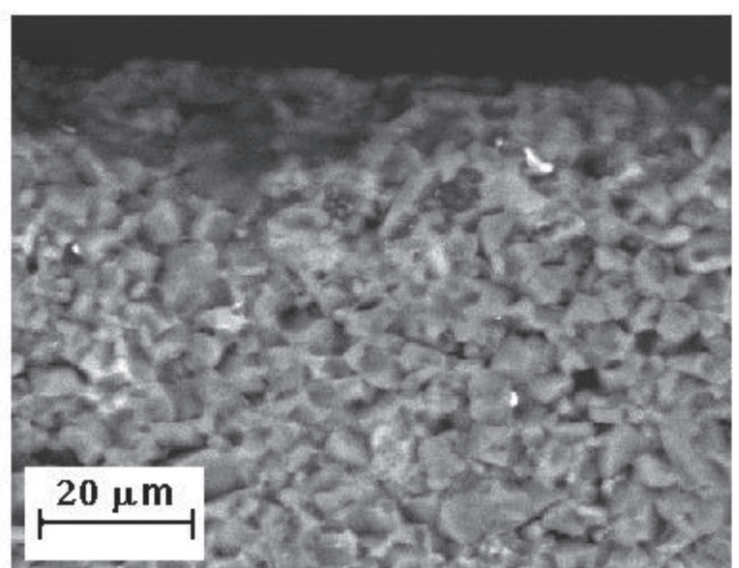

(d)

Figure 3. Cross section view of prepared composite-specimens as a function of cementation process time at $500{ }^{\circ} \mathrm{C}$. a) 1 hour, b) 2 hours, c) 4 hours and d) 8 hours.

Figure 4 shows a cross section SEM-view of alumina-3 vol.\% Ti specimen after the cementation process. EDS-microanalysis conducted both at the white particles at the edge and in the core of the sample confirmed the existence of elemental carbon, particularly being more concentrated at the specimen's edge. As long as the qualitative analysis is conducted at inner zones of the composite, the carbon concentration diminished. Not evident from this picture, there is a certain surface layer displaying a slightly different color contrast with respect to the $\mathrm{Al}_{2} \mathrm{O}_{3}$-bulk matrix. Such contrast, in practice exhibited similar texture to the cemented region. So that between the cemented layer and the non-cemented region, there is an intermediate zone which consists of partially-cemented Ti particles. Therefore, moving from the outermost surface part into the bulk of material can be detected three specific regions, featuring: 1) fully cemented metal particles, 2) partially cemented particles and 3 ) non cemented metallic particles.

Figure 5 shows depth of the cemented layer as a function of cementation time for alumina-based composites with different Ti content. There is an evident increment on the layer's depth as both, the cementation time and the Ti concentration rise. This on-growing behavior is not lineal and the curve's trend suggests eventual saturation of titanium-carbide at the surface, which accounts for its composite-nature.

Table 1 summarizes the relative density and some mechanical properties measured on the studied material. In Table 1 it can be observed that density increased as $\mathrm{Ti}$ content get higher in the composites. It is significant to note that microhardness was evaluated on the transversal section of the samples by indenting two different zones on the cemented specimens. First testing was carried out at the edge of the sample, whereas the other was practiced at the sample's centre. Microhardness for all studied samples with $\mathrm{Ti}$ is larger at the edge of specimens than that observed at their centre. This behaviour is due to the formation of hard $\mathrm{TiC}$ near to the edge of samples. The later takes place through the chemical reaction: $\mathrm{Ti}+\mathrm{C} \rightarrow \mathrm{TiC}$ $\left(\Delta \mathrm{G}=-43.2 \mathrm{Kcal}_{\mathrm{mol}}{ }^{-1}\right)^{6}$. The $\mathrm{TiC}$ formation takes place with carbon diffusion through the specimen's edge into the bulk. Cementation degree depends on the temperature and $\mathrm{Ti}$ concentration. In practice, it is thus possible to fabricate $\mathrm{Al}_{2} \mathrm{O}_{3}$-composites with $\mathrm{TiC}$ and $\mathrm{Ti}$ dispersions. On the other hand, at the samples's center there is just the presence of $\mathrm{Al}_{2} \mathrm{O}_{3}-\mathrm{Ti}$, and the formation of the $\mathrm{TiC}$ does not occur because diffusion of carbon cannot reach the sample's center, 
Table 1. Relative densities and mechanical properties measured in the cemented composites.

\begin{tabular}{ccccc}
\hline $\begin{array}{c}\text { System } \\
(\mathbf{v o l . \%} \mathbf{T i})\end{array}$ & $\begin{array}{c}\text { Relative density } \\
(\boldsymbol{\%})\end{array}$ & $\begin{array}{c}\text { Sample's edge hardness } \\
(\mathbf{G P a})\end{array}$ & $\begin{array}{c}\text { Sample's centre hardness } \\
(\mathbf{G P a})\end{array}$ & $\begin{array}{c}\mathbf{K}_{\mathrm{IC}} \\
\left(\mathbf{M P a . m} \mathbf{m}^{-1 / 2}\right)\end{array}$ \\
\hline 0 & 94.95 & $11.97 \pm 0.5$ & $11.94 \pm 0.5$ & $3.2 \pm 0.2$ \\
0.5 & 97.64 & $9.76 \pm 0.3$ & $6.80 \pm 0.3$ & $4.1 \pm 0.2$ \\
1.0 & 97.75 & $10.01 \pm 0.4$ & $9.13 \pm 0.3$ & $4.8 \pm 0.1$ \\
2.0 & 97.93 & $10.34 \pm 0.4$ & $9.69 \pm 0.4$ & $5.0 \pm 0.1$ \\
3.0 & 99.76 & $10.17 \pm 0.5$ & $7.09 \pm 0.3$ & $5.2 \pm 0.1$ \\
\hline
\end{tabular}
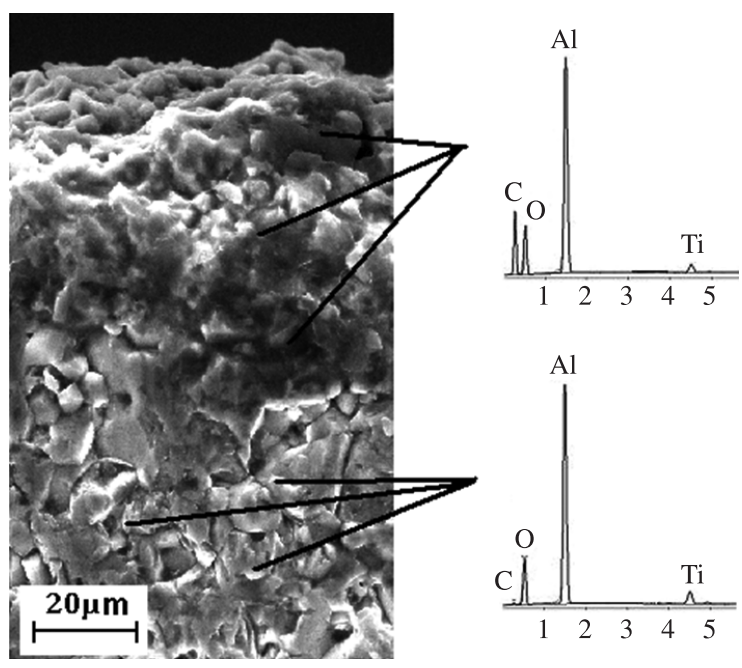

Figure 4. Cross section SEM-view and EDS analysis of alumina-3 vol.\% Ti specimen after cement process at $500{ }^{\circ} \mathrm{C}$ during 8 hours.

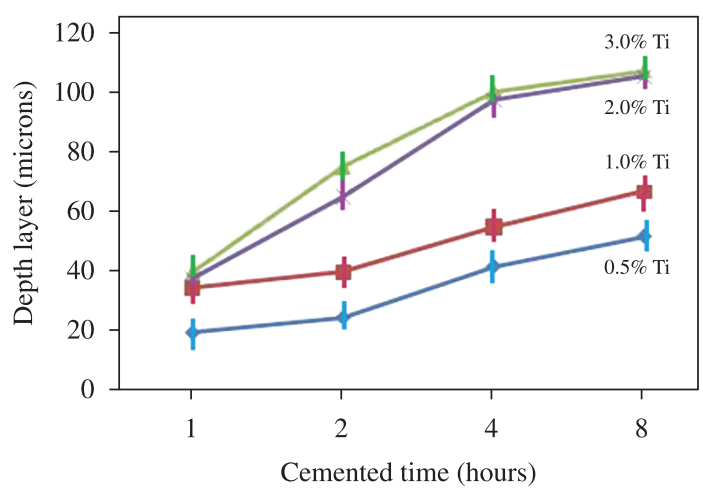

Figure 5. Depth of the cemented layer as a function of cementation time for alumina-based composites with different Ti content.

\section{References}

1. Shackelford JF and Doremus RH. Ceramic and Glass Materials: Structure, Properties and Processing. New York: Springer; 2010.

2. Lide DR, editor. Handbook of Chemistry and Physics. 90th ed. CRS Press; 2009.

3. Ighodaro OL and Okoli OI. Fracture toughness enhancement for alumina systems: A Review. International Journal of Applied Ceramic Technology. 2008; 5(3):313-323. http:// dx.doi.org/10.1111/j.1744-7402.2008.02224.x consequently hardness in this part of the sample is lower than hardness at the edge of the same one.

The magnitude of fracture toughness $\mathrm{K}_{\mathrm{IC}}$ attained in the studied materials is also reported in Table 1. For all studied cases, this strength parameter is superior to that of the pure alumina which is of about 3.2 $\mathrm{MPa}^{-1 / 2[3]}$. Due to these fracture toughness values it can be concluded that the metallic particle's dispersion into a ceramic matrix, as conducted in this work, may increase its toughness. Some authors have reported that the reinforcing mechanism operating in this kind of materials is associated to the crack bridging phenomena triggered by ductile metallic ligaments ${ }^{11}$. The high densification level conferred to the composites is another factor that greatly influences their toughness value because catastrophic cracking of specimens usually takes place as large voids are left in it.

\section{Conclusions}

Toughened $\mathrm{Al}_{2} \mathrm{O}_{3}$-matrix composites can effectively be synthesized by inducing very fine dispersions of $\mathrm{TiC}$ and $\mathrm{Ti}$, throughout a combination of experimental techniques, such as; high energy milling, pressureless sintering (Ar-atmosphere) and cementation packet process (vacuum). The later provided that $\mathrm{Al}_{2} \mathrm{O}_{3}, \mathrm{Ti}$ and activated carbon fine precursor powders are bring together as to react upon sintering forming a functionally cemented layer. This in-situ synthesis method produces composites with high density and do exhibit enhanced toughness, as compared to $\mathrm{Al}_{2} \mathrm{O}_{3}$-ceramics.

\section{Acknowledgements}

The microscopy laboratory facility given by IMP and processing laboratories of UAM-A, ESIQIE-IPN and UPV is appreciated. In addition, ERR are grateful to CONACyT by the support given to carry out this work through Project 132406.

4. Wessel JK. The Handbook of Advanced Materials. New York: John Wiley \& Sons; 2004. http://dx.doi. org/10.1002/0471465186

5. Functionally Graded Materials in the 21st Century: A Workshop on Trends and Forecasts. Kluwer Academic Publishers; 2000.

6. AccharW, Martinelli AE and Cairo CAA. Reinforcing $\mathrm{Al}_{2} \mathrm{O}_{3}$ with W-Ti mixed carbide. Materials Letters. 2000; 46(4):209-211. http://dx.doi.org/10.1016/S0167-577X(00)00171-3

7. Mathur $\mathrm{S}$ and Shen $\mathrm{H}$, editor. Nanostructured Materials and Systems: Ceramic Transactions, v. 214. American Ceramic, Mrityunjay Singh; 2010. 
8. Spencer CB, Córdoba JM, Obando N, Sakulich A, Radovic M, Odén $\mathrm{M}$ et al. Phase Evaluation in $\mathrm{Al}_{2} \mathrm{O}_{3}$ Fiber-Reinforced $\mathrm{Ti}_{2} \mathrm{AlC}$ During Sintering in the $1300-1500^{\circ} \mathrm{C}$ Temperature Range. Journal of the American Ceramic Society. 2011; 94(10):3327-3334. http://dx.doi.org/10.1111/ j.1551-2916.2011.04612.x

9. Acchar W and Fonseca JL. Sintering behavior of alumina reinforced with $(\mathrm{Ti}, \mathrm{W})$ carbides. Materials Science and Engineering A. 2004; 371(1-2):382-387. http://dx.doi. org/10.1016/j.msea.2003.09.089
10. Freiman S and Mecholsky JJ. The Fracture of Brittle Materials: Testing and Analysis. Wiley; 2012. http://dx.doi. org/10.1002/9781118147757

11. Rocha-Rangel E. Fracture Toughness Determinations by Means of Indentation Fracture. In: Cuppoletti J, editor. Nanocomposites with Unique Properties and Applications in Medicine and Industry. InTech; 2011. p. 21-37. http://dx.doi. org/10.5772/18127 